\title{
Los judíos de Maqueda (Toledo) y el monasterio de Santo Domingo el Antiguo de Toledo
}

\author{
Gonzalo Viñuales Ferreiro *
}

RESUMEN ABSTRACT

Documento inédito en el que se describe la ruptura del contrato de censo que habian establecido las monjas del monasterio bernardo de Santo Domingo el Antiguo de Toledo, con dos judíos de Maqueda (Toledo), a quienes habian entregado todas sus tierras en término de la citada villa a cambio de cierta cantidad de dinero que los hebreos no habian pagado durante varios años.
Unpublished document that describes the rupture of a census contract between the nuns of the Santo Domingo Bernardine Monastery at Toledo, and two jews of Maqueda (Toledo), who have all the lands of the monastery in this village in exchange for some money that these hebrews haven't paid for some years.

Hace dos años vio la luz nuestro trabajo sobre la población judía que habitó en la villa toledana de Maqueda durante la Baja Edad Media, en el que expusimos los aspectos más relevantes que caracterizaron a esta aljama hebrea ${ }^{1}$. Ahora, las tareas de la investigación han puesto frente a nuestra mirada un documento inédito ${ }^{2}$ de cierto interés que hace referencia

\footnotetext{
* Becario MEC (UNED).

VIÑuales FerReiro, Gonzalo: «Maqueda 1492. Judíos y judaizantes» en Espacio, Tiempo y Forma. Serie III. H. ${ }^{a}$ Medieval, vol. 11 (1998), pp. 383-404.

2 Archivo Histórico Nacional, en adelante, AHN. Clero. Libro 15039.
} 
a la ruptura de un contrato de censo establecido entre dos judíos de Maqueda y el monasterio de Santo Domingo el Antiguo de Toledo, y en el que se detallan las posesiones que se habían entregado a estos hebreos. A partir del mismo podemos indicar cúales fueron las líneas principales de la relación entre el relevante monasterio bernardo y la importante comunidad judía de Maqueda.

El 21 de mayo de 1492, ya en vísperas de la salida de los judíos de los reinos hispánicos, se presentaba ante Rodrigo de Vargas, escribano público de Toledo, Diego Pérez Tizón, mayordomo del monasterio de Santo Domingo el Antiguo de Toledo, y reclamaba para dicho convento los bienes que este monasterio había entregado en censo a los judíos de Maqueda Mosé Bahalu e Ysaque Açarrafe, quienes hacía tres años que no satisfacian las obligaciones del contrato:

[...] Yo Rodrigo de Vargas, escribano público del número de la muy noble ciudad de Toledo, doy fe que en veinte e un días del mes de mayo, año, del nascimiento de nuestro salvador Ihesu Christo de mil e cuatrocientos e noventa e dos años, por ante mí como escribano Mosé Bahalu e Ysaque Açarrafe, judíos de Maqueda, otorgaron que por cuanto la muy noble señora doña Teresa Alfonso de Vargas, por la gracia de Dios abadesa del monasterio de Sto. Domingo el antiguo desta dicha ciudad e las monjas e convento del dicho monasterio les ovieron dado para censo infiteosín para siempre jamás una heredad de tierras e olivas e parrales e zumacales que el dicho monasterio tenía en término de la villa de Maqueda en ciertos pedazos, según está cada pedazo nombrado e deslindado en la carta de censo que sobre la dicha razón pasó por ante Esteban López, escribano público, que Dios aya, con cargo de mil e cien mrs. e doce arrobas de aceite de censo e tributo infiteosín en cada un año para siempre jamás, e con cargo de las condiciones e tributos eclesiásticos que son a diezmo e a dos años a comisón. E por cuanto ellos han estado tres años continos que no han pagado el dicho tributo, e la dicha abadesa les ha hecho leer cartas para que viniesen a decir de su derecho sobre razón, e les querían tomar la dicha heredad por comisa según la condición del contrato. E por cuanto a la dicha señora abadesa se les fase cargo de conciencia averles de tomar la dicha heredad por la dicha pena de comisón e por les facer merced por las labores que en la dicha heredad han fecho, su merced les dio e pagó diez mil e quinientos mrs. e ellos los habían rescebido, de que se otorgaron por bien contentos e pagados a toda su voluniad, e en razón de la dicha paga renunciaron de las leyes del derecho que cerca della fablan. E asímismo la dicha señora abadesa les había fecho merced de todos los mrs. e aceite que le devían de tributos de la dicha heredad fasta hoy dicho día.

Por ende, otorgaron que dexaron, renunciaron, cedieron e traspasaron toda la dicha heredad, enteramente según e por la forma e manera que les fue dada al dicho censo, en la dicha señora abadesa e en las monjas e convento del dicho monasterio, para que de hoy dicho día en adelante la dicha heredad sea del dicho monasterio e fagan della todo lo que quisieren e por bien tovieren como de cosa propia del dicho monasterio [...] 
La carta de censo no se ha conservado. Sin embargo, según se desprende de este documento, el contrato se debió establecer, por lo menos, desde 1489. De acuerdo a las fórmulas, los contratos enfiteúticos se fijaban para siempre jamás, pero se limitaban con ciertas condiciones, siendo la principal el abono de un «alquiler» cada año. Si este no se pagaba, para lo que se imponía un plazo mínimo de dos años, los actores del mismo tenían la facultad de anularlo.

En este caso se fija el pago en 1.100 mrs. más doce arrobas de aceite, debido a que casi todo el cultivo que se encensa son olivos, pues en los contratos de censo es mucho más frecuente el pago en especie con cierto número de gallinas. Como los mencionados judíos no han satisfecho los pagos acordados, incluso aunque se les ha ampliado el plazo en un año, la abadesa, doña Teresa Alfonso de Vargas, debe ejecutar la pena de "comisón» por la que se anula la carta de censo y se restituyen las deudas con el propietario.

Ahora bien, en este caso concreto, aunque los hebreos no han abonado los maravedíes correspondientes, sí que han invertido dinero en esas tierras. Y este trabajo también cuenta. Así pues, la abadesa, en nombre de las monjas y del convento, entrega $10.500 \mathrm{mrs}$. a los mencionados judíos, y a la vez, les condiona la pena impuesta por no haber entregado los 1.100 $\mathrm{mrs}$. anuales y las 12 arrobas de aceite. Y lo más curioso es que lo hace exclusivamente movida por su conciencia.

Suponemos que esta razón era meramente formulativa pues la riqueza patrimonial entregada a censo era considerable. El 24 de mayo del mismo año, y por orden de Grabriel de Tapia, justicia mayor por el comendador de León en las villas de Maqueda, Torrijos, San Silvestre y Gerindote, se debía realizar un apeo y deslinde de las tierras entregadas a censo, con el fin de saber cúales y cúantas eran las heredades cuya propiedad debía volver al monasterio:

- [...] Yo Gabriel de Tapia, justicia mayor en las sus villas de Maqueda e Torrijos e las otras villas que de su señorío son, etc. por la presente mando a vos Ferrand Gómez y a vos Juan Alfón, vecinos de Santo Domingo, que vayáis a ver e apear toda la heredad de olivas e viñas e tierras e huertas e zumacales e parrales que son en término desta dicha villa de Maqueda e Santo Domingo e sus términos e tierra que son del monasterio de Santo Domingo el antiguo, de la ciudad de Toledo, el cual dicho heredamiento tenían a tributo Mosé Bahalu e Ysaque Açarrafe, judíos desta dicha villa de Maqueda, la cual les fue tenida por comisa, según paresce por el dexamiento que los dichos judíos hicieron por ante el reverendo doctor de Castro, vicario en la santa Iglesia de Toledo. Esto vos mando que así fagades e cumplades, por cuanto ante mí paresció Diego Pérez Tizón, mayordomo del dicho mo- 
nasterio. $E$ yo, visto el dicho su pedimiento, mandele dar este mi mandamiento para vos en la dicha razón, e por la presente mando a vos Ferránd Ximénez, alcalde en el dicho lugar, que tomedes e rescibades juramento en forma debida de derecho que digan $e$ declaren los dichos heredamientos del dicho monasterio suso dichos. E non fagades ende al, so pena de dos mil maravedíes a cada uno que lo contrario fisiere, para los muros desta dicha villa, esto faser pagándovos vuestro justo e debido salario. Fecho en la villa de Maqueda, veinticuatro días del mes de mayo de mil e cuatrocientos e noventa e dos años. Gabriel de Tapia. Alfón González.

$Y$ esto todo así fecho, luego fuimos a un olivar que se dice de la Dehesa, que está en término de Santo Domingo, en que hay en él treinta y nueve pies de olivas, que ha por linderos, de la una parte olivar del Mariscal Mateo de Ribadeneira; e de la otra, olivar del judío Franco; e de la otra parte, la dehesa; e de la otra parte, el camino que va de Maqueda a Torrijos.

Deste dicho pedazo de olivar fuimos a otro olivar, que se dice el Enzinilla, que está en término de Val de Santo Domingo, en que hay cuarenta e un pies de olivas, que ha por linderos el olivar del Enzinilla, el cual le cerca todo y es de la capellanía de San Julián de la villa de Santolalla.

Deste dicho pedazo de olivar fuimos a otro olivar, que se dice del Enebro, que está en término de $\mathrm{Val}$ de Santo Domingo, en que hay treinta pies de olivas, que ha por linderos, de la una parte olivar de Simuel Toledano; e de la otra parte, la raya que parte la tierra de Maqueda e Val de Santo Domingo; e de la otra parte, olivar de los quintos de Val de Santo Domingo.

Item, deste dicho pedazo de olivar fuimos a otro olivar, que se dice el olivar del Ganado, con un pedazo de tierra en que hay cincuenta e un olivas, que ha por linderos, de la una parte olivar de herederos de Pero López, recabdador; e de la otra parte, herial del Sordo; e de la otra parte, el sendero que va al olivar de la Dobla.

Item, deste dicho pedazo de olivar fuimos a otro olivar, que se dice el Taladro, que está en término de Val de Santo Domingo, con un zumacalejo, en que hay ochenta pies de olivas, que ha por linderos, de la una parte olivar de herederos de Ferránd Alfón de Toledo, que Dios aya; e de la otra parte, olivar de Yudá Franco; e de la otra parte, la senda que va a la Loma.

$Y$ deste dicho pedazo de olivar fuimos a otro olivar, que se dice el Atarta, que está en término de Maqueda, con un pedazo de tierra e con un zumacal en que hay diez e siete pies de olivas, que alinda, de la una parte con tierra e zumacal del señor comendador Martín de León; e de la otra parte, con tierra de la iglesia de Santa María de Maqueda; e de la otra parte, olivar de Jaco Abenanbrán, judio de Maqueda.

Item, deste dicho pedazo de olivar fuimos a un pedazo de tierra parral en que hay dos pies de olivas, que alinda con olivas e parral de Mosé Abenzunbal; e de la otra parte, con tierra de Alvaro de Vargas; e de la otra parte, con majuelo de Haluzo.

Item, deste pedazo de tierra fuimos a un olivar que está en término de Maqueda, que se dice el Carmenón, con ciertas cepas en que hay en él, treinta y ocho pies de olivas, que ha por linderos, de la una parte parral de 
Bahalu, judío de Santolalla; e de la otra parte de Mosé Gavisón; e de la otra parte, los machos de Ferrando de Contreras; e de la otra parte, heredad de don Çiza Abenzabad.

Item, deste dicho olivar fuimos a otro olivar, que se llama la Pontezilla, $e$ las espadas con un pedazo de tierra calma en que hay veinte olivas, que han por linderos, de la una parte olivar de Catán; e de la otra parte, heredad de Franco, judío de Maqueda.

Item, otro pedazo de olivar que se dice el Espada en que hay nueve pies de olivas, que está en término de Maqueda, que ha por linderos, de la una parte olivar de Mosé Abenzabal; e de la otra parte, Mosé Catán; e de la otra parte, Mosé Abentamuz.

Item, otras tres olivas que están en término de Maqueda, las cuales están entre entramas aguas.

Item, otro olivar que se dize el Pradorredondo en que hay cuarenta y siete pies de olivas, que ha por linderos, de la una parte el camino viejo que viene de Maqueda a Val de Santo Domingo; e de la otra el prado de Villalna; e de la otra, heredad de Maestre Ysaque; e de la otra majuelo de Pantoja.

Item, otro pedazo de olivar que se dice la Carcava que está en el término de Maqueda, y así mismo se llama Tijareros, en que hay cinco olivas e un pedazo de tierra calma, que ha por linderos, de la una parte heredad de Antón Graviel, e la qual es de la iglesia; e de la otra, heredad de Rabí Simuel Alocanén.

Item, otro pedazo de olivar con ciertas cepas de zumaque en que hay treinta y dos pies de olivas, que han por linderos, de la una parte heredad de Mosé Açarrafe; e de la otra parte, olivar de Calderón; e de la otra parte, el camino que va de Maqueda al molino.

Item, otro pedazo de olivar que está en término de Maqueda, en que hay catorce olivas, que han por linderos, de la una parte heredad de la cofradía de San Miguel de la dicha villa; e de la otra, olivar que se llama los Machos de don Mosé Cana, el qual dicho olivar se dice el Potrillo.

En total, el monasterio de Santo Domingo había acensado a Mosé Bahalu e a Ysaque Açarrafe 428 pies de olivas, lo que en la práctica equivalía a todas las heredades que el monasterio poseía en el término de Maqueda y Val de Santo Domingo. Esto supone que el monasterio dejaba en manos de estos dos judíos concretos el control de todas sus tierras en Maqueda. Algo parecido ya se había producido en relación a judios de esta villa, cuando en 1404, el abad de San Vicente, arrendaba por cinco años, a don Abrahem Aben Halegua y a don Semtob Franco, judío de Maqueda, todas las tierras de pan llevar que pertenecían a la abadía en Pero Véquez, Hurtada y Val de Santo Domingo ${ }^{3}$. No fueron los únicos, ya que

3 León Tello, Pilar: Judíos de Toledo. Madrid. 1979. CSIC, vol. II, p. 206, n. 694. 
también el monasterio de Santo Domingo el Real de Toledo, entregó en censo a judíos de Maqueda muchos de los bienes rústicos con los contaba en tierra de esta villa toledana, en término de Val de Santo Domingo ${ }^{4}$.

Esta enorme confianza depositada por las monjas en la gestión del patrimonio se basaría en la capacidad de pago y rentabilidad de los mencionados judíos ${ }^{5}$, y en que, aunque ambos judíos pertenecían a familias asentadas en la villa de Maqueda, por lo menos desde el último tercio del siglo xv - los Bahalu y los Açarrefe-, muchos de los hebreos que recalaron en la villa de Maqueda tras las revueltas del año 1391 procedían de la capital del Tajo, lo que habría facilitado las relaciones entre instituciones toledanas y judios de Maqueda.

De Mosé Bahalu, sabemos que se convirtió al cristianismo y adoptó el nombre de Lope Ferrández. Su situación económica en vísperas de la expulsión no debía ser muy boyante, ya que su casa estaba remitida por deudas a acreedores. Sin embargo, en 1464 había sido, junto con don Yudá Alocanén, arrendador de las alcabalas de Maqueda, del cabildo de la Catedral de Toledo $^{6}$.

Ysaque Açarrafe había rematado en 1491 las rentas del excusado del arciprestazgo de Maqueda en $33.075 \mathrm{mrs}$. y estaba encargado de su recaudación. Tampoco son favorables los datos que conocemos de su nivel económico poco antes de la salida de los judíos, pues había empeñado un majuelo a Jaco Bahalu (¿hermano quizá de Mosé?), por 3.000 maravedíes.

Esta desfavorable coyuntura económica, unida a la intranquilidad provocada por la necesidad de conversión o de huida, explica la falta de cumplimiento en las condiciones del contrato de censo. Resulta más extraña la actitud de la abadesa quien, en un momento propicio para el abuso y el engaño para con unos judíos bastante indefensos, resuelve abonar las mejoras realizadas en las dichas tierras favoreciendo claramente a sus acensuatarios, lo que demuestra que aunque la obligación de salir de los reinos impuso tratos vejatorios e insultantes para con la minoría judía, hubo algunas excepciones donde la cordialidad y los años de contacto hicieron menos traumático el exilio.

\footnotetext{
Ibid, vol. II. núms. [859] [862] [881] [882] [886] [897] [959] [960] [964] [973] [989] [1002].

Los acuerdos entre la comunidad bernarda de Sto. Domingo y los judíos no eran nuevos, pues ya en 1469 las monjas arrendaron a un judio de Toledo, don Ysaque Ardutel, una heredad situada también en tierra de Maqueda. AHN. Clero. Libro 15039.

6 Archivo Histórico Provincial de Toledo. Hacienda. H. 1933, n. ${ }^{\circ} 32$ bis. REG, León TelLo, P.: Judios de Toledo, Madrid, 1979, vol. II, pp. 352-353.
} 
Los judios de Maqueda (Toledo) y el monasterio de Santo Domingo el Antiguo de...

Al exponer las propiedades que habían sido dadas en censo a los judíos, se indican, para favorecer su ubicación, las tierras colindantes. Entre los poseedores se nombra cierto número de judíos, también vecinos de la villa de Maqueda. Todos ellos son miembros de importantes familias judías residentes en esta villa: Abenanbrán, Abençubal, Abentamuz, Alocanén, Catán, Franco y Gavison, y todos ellos cuentan con un interesante patrimonio destacando entre ellos, Mosé Abençubal, conocido bajo el sobrenombre de «el rico", o Mosé Gavisón, quien desempeñaba algún cargo en el contexto de la comunidad hebrea?

Resulta bastante complejo afirmar si estos judíos trabajaban directamente sus tierras o las explotaban jornaleros, a quienes se las entregaban a cambio de una renta. Yo me inclinaría por indicar que debido al elevado número de judíos que a fines del siglo xv habitan en Maqueda, más de 300 familias, y a que la villa, situada en una paraje eminentemente agrícola, y no excesivamente grande, no tendría suficiente demanda de hebreos dedicados exclusivamente a actividades artesanales o de servicios, y por tanto algunos de ellos se verían obligados a trabajar sus tierras. No a todos, sino a aquellos cuya situación económica o su estatus dentro de la comunidad les impidiera vivir apartados de las tareas del campo.

7 LEÓN TELlo, P.: Op. cit., vol. I, pp. 325-326. 